\title{
Indhold 2010
}

ARTIKLER . . . . . . . . . . . . . .

Petter Asp: Ne bis in idem . . . . . . . . . . . . . . . . . . 508

Flemming Balvig m.fl.: Den nordiske retsbevisthedsundersøgelse .... 232

Asa Bergenheim \& Jonas Liliequist:

"Visa aktning för din far och din mor" . . . . . . . . . . . . . . . . . 179

James Bonta: Understanding What Works .............. 281

Martin Borgeke: Hur säkerställer vi en enhetlig påföljdsbestämning? . 401

Bent Clausen: Om strafudmåling og lovmotiver ............. 412

Nils Dalseide: Kontroll av ekstraordinære etterforskningsmetoder . . . 296

Anders Danielsson: Framtidens polis och framtidens polisutbilding . . 275

Felipe Estrada: Våld som ett (bra) samhällsproblem ........... 320

Dan Frände: Nolltolerans och begatellbrott . . . . . . . . . . . . . . . 394

Vagn Greve: Den strafferetlige behandling af bagatelagtige sager . . . $\quad 379$

Vagn Greve:

Internationaliseringens betydning for den nationale strafferet $\ldots \ldots$. Lene Hansen m.fl:

Medicinske fund og det retslige udfald hos seksuelt misbrugte børn .. Hanns von Hofer: Långsiktiga prognoser av platsbehovet på fängsler May-Len Skilbrei Charlotta Holmström: Nordisk prostitusjonspolitikk Per Ole Johansen: I skyggen av det norske ikon ............. Lars Korsell \& Paul Larsson: Organiserad brottlighet i Norden ..... Pål Lagestad og Hild Rønning: Sunn fornuft og bedre vitende . . . . . . Lars Bo Langsted: Den retlige regulering af corruption I Norden .... . Paul Larsson: Fra armesterke bondesønner til akademikerbarn . . . . . . Paul Larsson \& Lars Korsell:

Organiseret kriminalitet, en kunnskapsstatus . ............. Claes Lernestedt: Finns det grader i helvetet? .............. Inger-Lise Lien: Bandekriminalitet og forebygning . ........... Magnus Matningsdahl: Politikernes innflytelse på straffutmålingen .. Gorm Toftegaard Nielsen:

Er den Europæiske Menneskerettighedsdomstol en trussel... . . . . . .

Maria Libak Pedersen: Når unge begår vold . . . . . . . . . . . .

Jon Petter Rui: Ne bis in idem . . . . . . . . . . . . . .....

Margret Saemundsdóttir: Sosioøkonomiske kjennetegn på... . . . . . . 
Joakim Thelander: Bofors-Indienaffären

- ett fall av omdiskuterad svensk vapenexport ..............

Per Ole Träskman:

De straffrättsliga principerna och den europeiska.............

Minna Viuhko: Mäste man altid betala? . . . . . . . . . . . .

\section{BOGANMELDELSER}

Lin Adrian af HOWARD ZEHR: Ret - en lille bog om ret, uret og

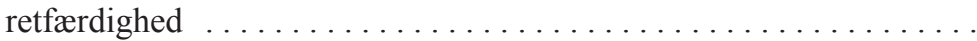

Lars Højgaard Andersen af: CHRIS GROVER: CRIME AND

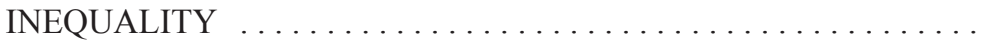

Petter Asp af GORM TOFTEGAARD NIELSEN: Strafferet 2.

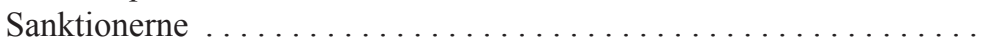

Niels Christie af KJETIL S. ØSTLI: Politi og Røver . . . . . . . . .

Peter Garde af ARMIN ENGLÄNDER: Grund und Grenzen der

Nothilfe . . . . . . . . . . . . . . . . . . . . . . . . . . . . .

Peter Garde af ULRICH SIEBER \& KARIN CONILS: Nationales Strafrecht in.. . . . . . . . . . . . . . . . . . . . . . . . . . .

Vagn Greve af NILS CHRISTIE: Små ord for store spørgsmål . . . . . .

Jonas Havelund af ANDERS GREEN: Fotboll och huliganism.

Utvekling.. . . . . . . . . . . . . . . . . . . .

Nadja Kirchhoff Hestehave af FRANK V. GEMERT, DANA

PETERSON OG INGER-LISE

LIEN: Street gangs, migration and ethnicity $\ldots \ldots \ldots \ldots \ldots \ldots$

Lars Korsell af: KARSTEN INGVALDSEN OCH VANJA

LUNDGREN SØRLI (RED.): Organised crime - norms, markets,

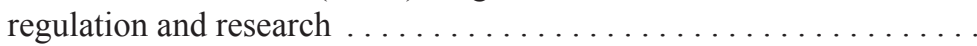

Peter Kruize af STEFAN FAFINSKI: Computer Misuse - Response,

regulation...

Paul Larsson af STEVE HALL M.FL.: Criminal Identities and

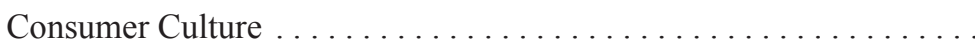

Peter Lauritsen af KATJA FRANKO AAS, HELENE OPPEN

GRUNDHUS OG HEIDI MORK LOMELL: Technologies of

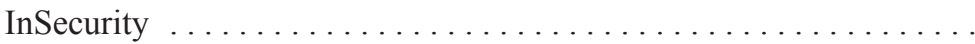

Beth Grothe Nielsen af OLE-JOHN EIKELAND: Education in Nordic

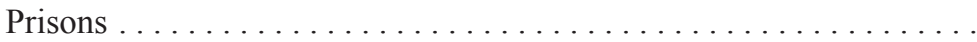

Leif Petter Olaussen af JANE WOOD \& THERESA GANNON:

Public opinion and criminal justice $\ldots \ldots \ldots \ldots \ldots \ldots \ldots$ 
Jens Røn af ANNEMETTE MØLLER-SØRENSEN OG

ANETTE STORGAARD (RED.): Jurist uden omsvøb - festskrift til Gorm Toftegaard Nielsen ............................ 94

Marit Wårum af JESPER RYBERG (RED.): Løsladt - og hvadså? . . $\quad 208$

\section{DIVERSE}

Program for Nordisk Kriminalistmøde

Lars Barfoed: Justitsministerens tale ved

Nordisk Kriminalistmøde 2010

William Rentzmann:

Velkomst ved Nordisk Kriminalistmøde i København . . . . . . . . . . 